\title{
Studi Pendahuluan Keanekaragaman Hymenoptera Parasitoid di Kawasan Hijau Kampus UNRI, Panam
}

\author{
Arini $^{1 *}$, Meyla Suhendra ${ }^{1}$, Ennie Chahyadi ${ }^{1}$, Ninik Nihayatul Wahibah ${ }^{1}$, Ahmad Parlaongan ${ }^{2}$ \\ ${ }^{I}$ Fakultas Matematika dan Ilmu Pengetahuan Alam, Jurusan Biologi, Universitas Riau \\ ${ }^{2}$ Program Studi Kehutanan, Universitas Muhammadiyah Jambi \\ *email: arini@lecturer.unri.ac.id
}

Key word:

Habitat change

Invasive species

Urbanization

\begin{abstract}
Article History
Received:

11/12/2021

Revised:

19/12/2021

Accepted:

30/12/2021

Kata kunci:

Spesies invasif

Urbanisasi

Perubahan

habitat

ABSTRAK

Berbagai modifikasi terhadap lingkungan dilakukan oleh manusia untuk memenuhi kebutuhan dalam kehidupan dan hal ini berdampak terhadap biodiversitas termasuk serangga. Aktivitas urbanisasi seperti dibangunnya areal perkotaan atau pemukiman, merupakan salah satu bentuk modifikasi lingkungan yang memiliki dampak terhadap biodiversitas tersebut. Kampus UNRI dengan lanskap di dalamnya dapat diamati untuk melihat biodiversitas serangga yang ada di sana. Penelitian ini bertujuan untuk memperoleh data dan informasi mengenai keanekaragaman serangga, khususnya Hymenoptera parasitoid di kawasan hijau Kampus UNRI. Pengambilan sampel serangga tersebar pada delapan lokasi dengan metode penjaringan pada AgustusSeptember 2019. Sampel serangga yang diperoleh kemudian dikoleksi di dalam tabung koleksi dan diidentifikasi hingga tahapan morfospesies. Secara keseluruhan individu serangga yang paling melimpah berasal dari Ordo Diptera (49\%), Hymenoptera (29\%), dan Hemiptera (20\%), kemudian Thysanura (Thrips sp.), Coleoptera, Lepidoptera, Odonata, dan Orthoptera. Ordo Hymenoptera yang diperoleh berasal dari sembilan superfamili dan 16 famili dengan individu paling melimpah adalah Chalcididae (26\%), Braconidae (25\%), diikuti dengan Eulophidae dan Scelionidae masingmasing sebesar $12 \%$. Hasil yang diperoleh menggambarkan keanekaragaman Hymenoptera parasitoid yang terdapat di kampus berkaitan erat dengan keberadaan serangga inang dan keanekaragaman dan kelimpahan tumbuhan pada kawasan hijau.
\end{abstract} \begin{abstract}
Modifications to environment are carried out by humans has impacts on biodiversity including insects. Urbanization activities, such as the construction of urban areas or settlements, are form of environmental modification that has impacts on insect biodiversity. Universitas Riau with its landscape can be observed to study about insect biodiversity. Sampling was done in eight locations with sweep net method. Overall, the most abundant individual insects came from Diptera (49\%), Hymenoptera (29\%) and Hemiptera (20\%), then Thysanura, Coleoptera, Lepidoptera, Odonata and Orthoptera. The order Hymenoptera obtained from nine superfamilies and 16 families with abundant numbers were Chalcididae (26\%), Braconidae (25\%), followed by Eulophidae and Scelionidae $12 \%$ respectively.
\end{abstract}

Copyright (C) 2022 LPPM Universitas Indraprasta PGRI. All Right Reserved

\section{PENDAHULUAN}

Manusia melakukan berbagai modifikasi lingkungan untuk memenuhi kebutuhan hidupnya dan hal ini berdampak terhadap biodiversitas, termasuk serangga, pada lingkungan tersebut (Vitousek et al., 1997). Berbagai penelitian menunjukkan bahwa peningkatan intensitas penggunaan lahan memiliki pengaruh terhadap penurunan spesies serangga polinator, baik dari sisi kekayaan spesies maupun sisi fungsional serangga polinator (Rader et al., 2014). Asfiya et al. (2015) menyebutkan bahwa sistem agroforestri yang intesif akan memberikan dampak yang signifikan terhadap komposisi spesies semut bahkan dapat berujung pada hilangnya spesies semut alami di hutan hujan tropis. Selain secara langsung berpengaruh terhadap penurunan spesies suatu serangga, modifikasi berupa transformasi habitat alami juga mampu mempengaruhi proses-proses 
ekologi dan interaksi antara berbagai level tropik seperti musuh alami, herbivora, dan tanaman inang (Firbank et al., 2008).

Pengaruh modifikasi lahan terhadap biodiversitas serangga banyak dipelajari pada kasus transformasi lahan seperti alih fungsi hutan menjadi perkebunan atau agroforestri. Sementara di sisi lain, pengaruh transformasi habitat yang disebabkan dengan urbanisasi, seperti dibangunnya areal perkotaan atau pemukiman, banyak berkaitan dengan epidemiologi dan pengelolaan hama (Mcintyre \& Hope, 2008). Padahal Wheeler (2008) menjelaskan bahwa biodiversitas fauna, termasuk serangga, dapat dipahami dengan melihat areal urbanisasi termasuk kampus sebagai bagian dari ekosistem. Suatu kampus umumnya dibangun dengan desain tertentu dan ditemukan habitat yang beragam seperti lapangan terbuka (open space), taman, sungai atau kolam, hingga hutan pendidikan dan arboretum. Sehingga kampus dengan lanskap di dalamnya bahkan bisa membantu menjaga keseimbangan bidoversitas serangga sekaligus berperan penting dalam berbagai proses ekologi (Wheeler, 2008).

Kampus Universitas Riau (UNRI) Panam merupakan kampus utama yang bertempat di Kampus Bina Widya KM 12.5 Simpang Baru, Pekanbaru. Luas keseluruhan kampus adalah 338.264 ha (Nurdin, 2007) yang selain berisi bangunan untuk berbagai proses pendidikan juga terkategori kampus 'hijau' karena masih banyak terdapat pepohonan, ruang terbuka, kebun buah, kolam, termasuk science park. Keberadaan berbagai jenis habitat ini tentu memiliki kaitan yang erat dengan keberadaan serangga di sana, termasuk Hymenoptera. Hymenoptera merupakan ordo serangga terbesar ke-tiga setelah Lepidoptera dan Coleoptera (Grimaldi \& Engel, 2005). Di alam, sekitar $80 \%$ dari kelompok Hymenoptera didominasi oleh spesies parasitoid (Hymenoptera parasitika) di samping spesies lain yang berperan sebagai fitofag, predator, atau polinator (Quicke, 1997). Sharkey (2007) menyebutkan bahwa parasitoid sensitif terhadap perubahan dan kerusakan habitat. Perbedaan habitat diduga dapat mempengaruhi keanekaragaman spesies Hymenoptera parasitika yang hidup di dalamnya terutama kekayaan spesies. Data keanekaragaman ini dibutuhkan untuk menggambarkan spesies atau morfospesies serangga Ordo Hymenoptera di tengah berbagai pembangunan di Kampus UNRI atau proses urbanisasi di Kota Pekanbaru secara umum namun informasi dasar mengenai morfospesies Hymenoptera di kampus UNRI ini belum pernah dilaporkan. Dengan demikian, penelitian ini bertujuan untuk memperoleh data dan informasi mengenai keanekaragaman serangga, khususnya Hymenoptera parasitoid di kawasan hijau Kampus UNRI.

\section{METODE PENELITIAN}

\section{Penentuan Lokasi Pengambilan Sampel}

Lokasi pengambilan sampel ditentukan dengan melihat gambaran Kampus Universitas Riau (Gambar 1 dan Tabel 1). Kampus Universitas Riau memiliki beberapa taman, lapangan olahraga, jalanan dengan pepohonan/bunga-bungaan pada pinggirannya, dan sisanya berupa bangunan. Taman, lapangan olahraga, dan pepohonan di pinggir jalan tentu menjadi habitat bagi berbagai spesies serangga, termasuk Hymenoptera di Kampus UNRI, Panam.

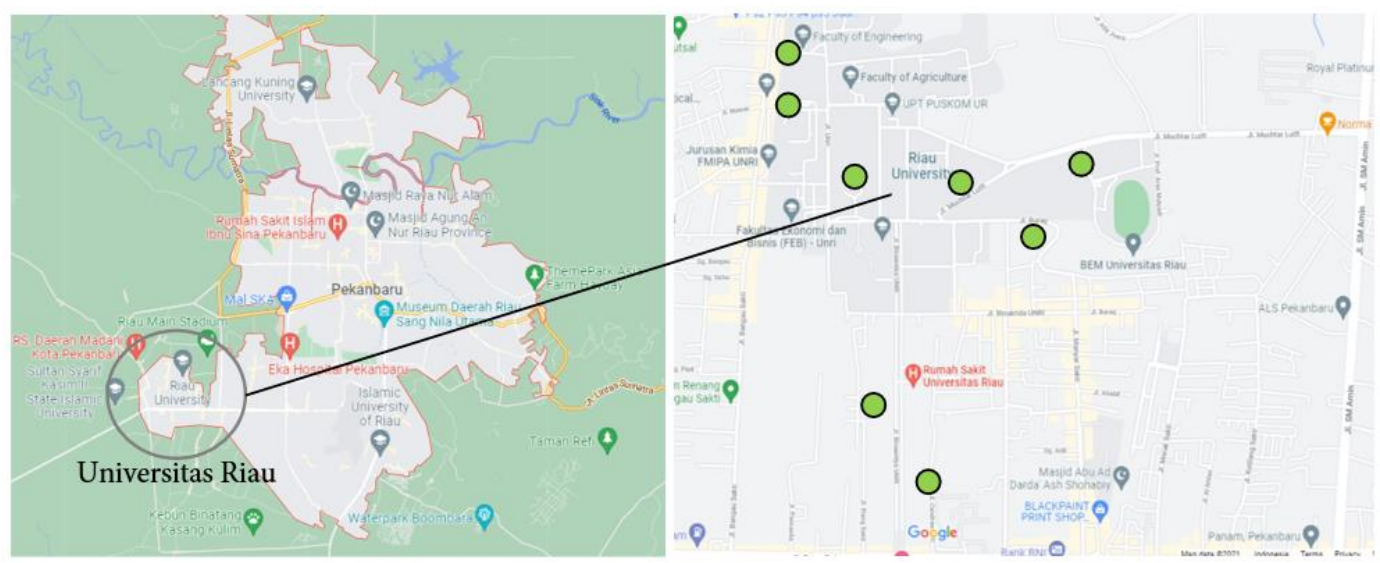

Gambar 1. Peta Kota Pekanbaru dan posisi kampus UNRI (kiri) dan persebaran titik pengambilan sampel (kanan, titik berwarna hijau) 
Tabel 1. Gambaran lokasi pengambilan sampel

\begin{tabular}{lll}
\hline Lokasi dan Kode & Gambaran Lokasi \\
\hline Lahan Kebun (LK) & & \\
& & \\
\end{tabular}

Lahan Teknik (LT)

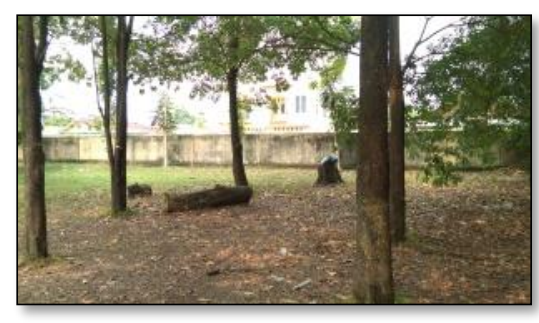

Eco Edu Park (EE)
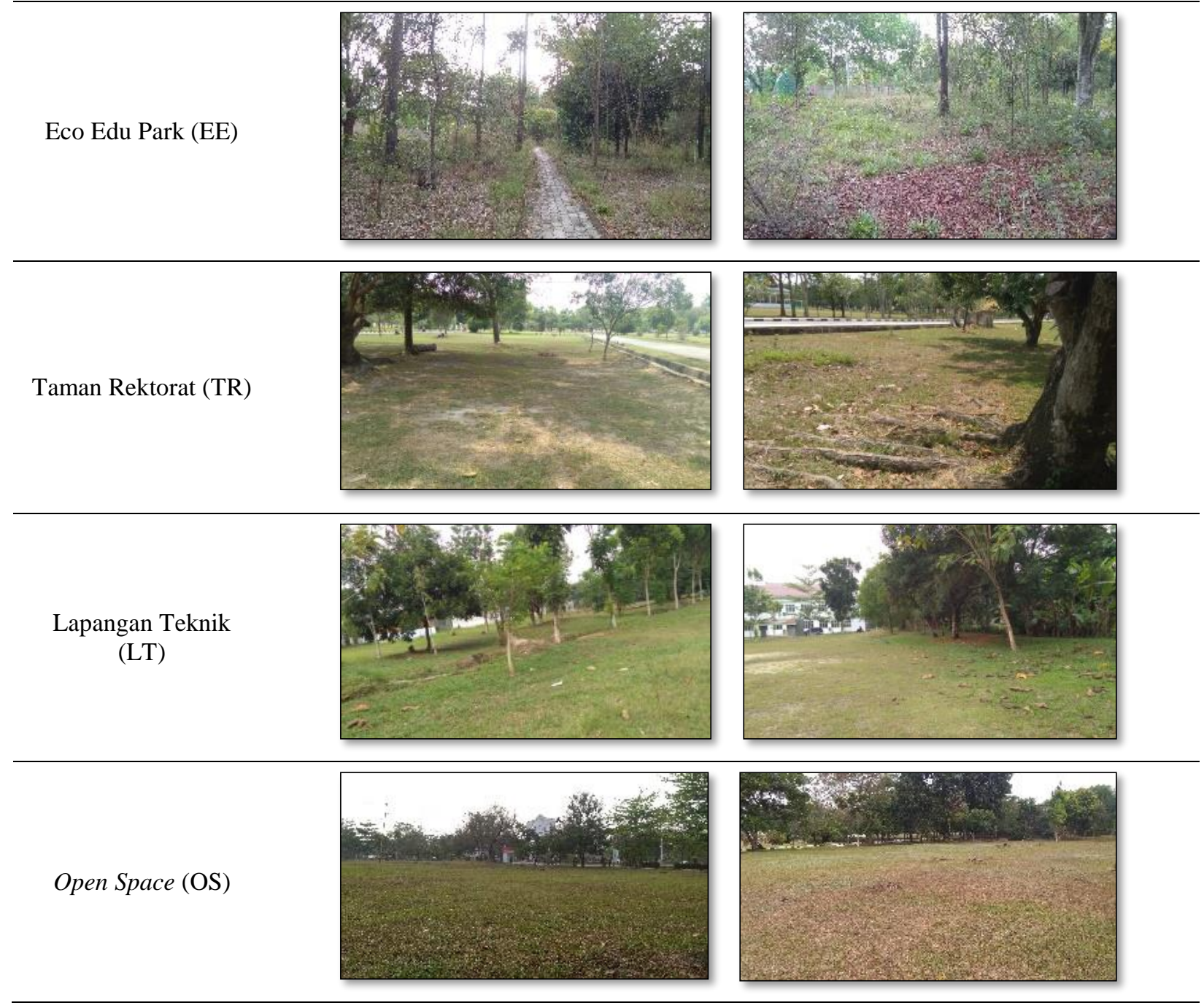
Sains Park (SP)
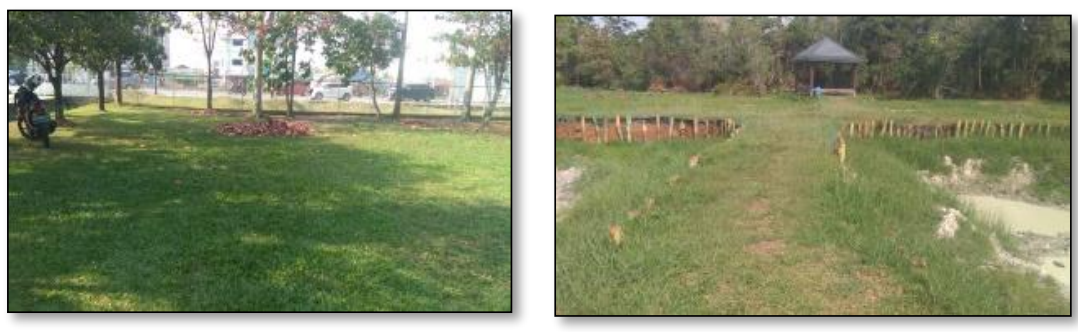

Taman Buah (TB)
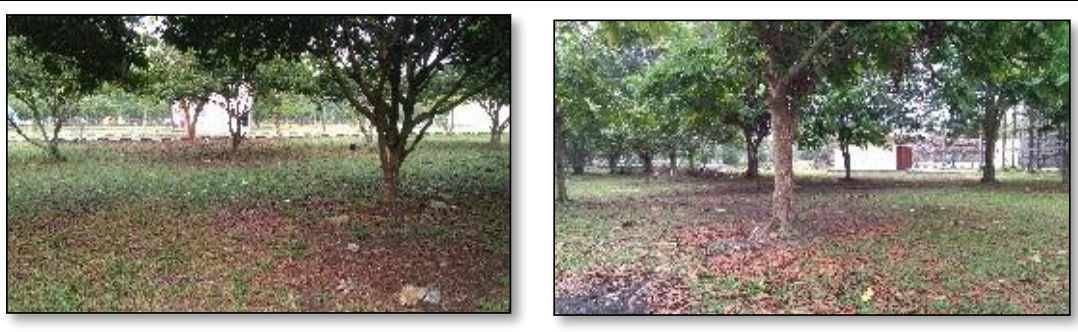

\section{Pengambilan Sampel dan Identifikasi Serangga}

Pengambilan sampel serangga dilakukan pada bulan Agustus 2019 dengan menggunakan metode penjaringan atau sweep net. Pada setiap lokasi dilakukan pengambilan sampel dengan menetapkan lima titik (purposive sampling). Pada setiap titik akan dilakukan penjaringan sebanyak 10 ayunan tunggal dengan jaring serangga berdiameter $50 \mathrm{~cm}$. Waktu pengambilan sampel adalah setiap pagi pada pukul $07.00-10.00$ WIB. Serangga yang diperoleh dari setiap titik pengambilan sampel akan dipisahkan dan disortasi berdasarkan ordo. Ordo Hymenoptera akan diindentifikasi menggunakan kunci identifikasi hingga tingkat morfospesies. Proses identifikasi menggunakan buku Insect of Australia, Hymenoptera of the World, Handbook of Nearctic Chalcidoidea. Proses identifikasi mengunakan mikroskop stereo Onglai Fixtool M-2.

\section{HASIL DAN PEMBAHASAN}

Berdasarkan hasil koleksi dan identifikasi, secara keseluruhan individu serangga yang paling melimpah berasal dari Ordo Diptera (49\%), Hymenoptera (29\%) dan Hemiptera (20\%) (Gambar 2). Ordo serangga lain yang juga diperoleh melalui metode penjaringan adalah Thysanura (Thrips sp.), Coleoptera, Lepidoptera, Odonata, dan Orthoptera. Tingginya kelimpahan Ordo Diptera di Kampus UNRI diduga karena tingginya aktivitas manusia di dalam kampus dan lokasi kampus yang berbatasan langsung dengan area pemukiman masyarakat dan areal pertokoan. Ordo Diptera merupakan salah satu ordo serangga kosmopolitan dengan kelimpahan spesies dan individu terbesar di dunia dan berhasil mengolonisasi hampir setiap habitat (terrestrial and aquatic habitats) (McAlpine, 1981; Merritt et al., 2009).

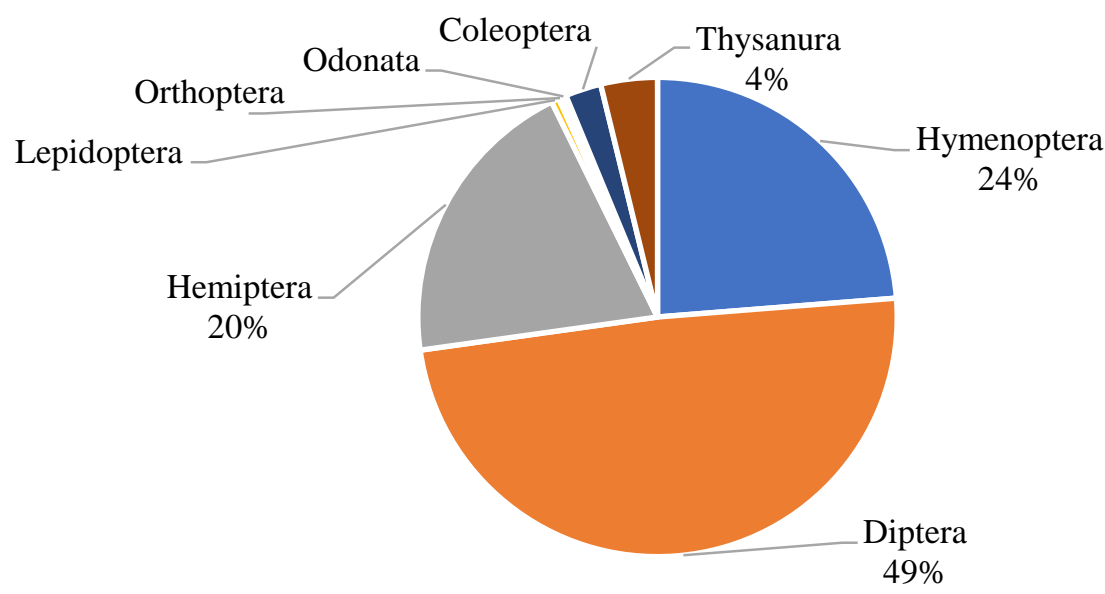

Gambar 2. Ordo serangga hasil koleksi 
Ordo Hymenoptera merupakan ordo dengan kelimpahan individu tertinggi kedua yang diperoleh dengan jumlah 137 individu dari sembilan superfamili dan 16 famili (Tabel 2). Famili dengan individu paling melimpah adalah Chalcididae (26\%), Braconidae (25\%), diikuti dengan Eulophidae dan Scelionidae masingmasing sebesar $12 \%$ dari keseluruhan individu yang diperoleh. Tingginya kelimpahan Famili Chalcididae diduga berkaitan dengan inang yang tersedia. Chalcididae merupakan parasitoid primer bagi Diptera, Lepidoptera, serta beberapa Coleoptera, dan Hymenoptera (Goulet \& Huber,
1993). Hasil penelitian yang dilakukan di area urban lainnya juga menunjukkan bahwa parasitoid Chalcididae banyak ditemukan dan memiliki tingkat parasitisasi yang tinggi pada Ordo Diptera (Marchiori, 2019) dan hal ini sejalan dengan kelimpahan Diptera di Kampus UNRI. Keanekaragaman dan kelimpahan serangga herbivora dipengaruhi oleh habitat serta keanekaragaman dan kelimpahan tumbuhan di sana dan tingginya keanekaragaman dan kelimpahan serangga herbivora berbanding lurus terhadap keanekaragaman dan kelimpahan musuh alaminya termasuk parasitoid.

Tabel 2. Superfamili dan famili Hymenoptera dari kawasan hijau kampus UNRI

\begin{tabular}{|c|c|c|c|c|c|}
\hline No. & Superfamily & Famili & $\begin{array}{c}\text { Total } \\
\text { Morfospesies }\end{array}$ & $\begin{array}{c}\text { Total } \\
\text { Individu }\end{array}$ & $\begin{array}{c}\text { Taxa Serangga Inang } \\
\text { (Hagen et al., 1999; Goulet \& Huber, 1993) }\end{array}$ \\
\hline 1 & Ceraphronoidea & Ceraphronidae & 1 & 2 & $\begin{array}{l}\text { Diptera, Thysanoptera, Lepidoptera, } \\
\text { Neuroptera, Hymenoptera }\end{array}$ \\
\hline 2 & Cinypoidea & Eucoilidae & 1 & 1 & Diptera \\
\hline 3 & Chrysidoidea & Drynidae & 1 & 1 & Hymenoptera \\
\hline \multirow{6}{*}{4} & \multirow{6}{*}{ Chalcidoidea } & Chalcididae & 4 & 36 & $\begin{array}{l}\text { Diptera, Lepidoptera, Coleoptera, dan } \\
\text { Hymenoptera }\end{array}$ \\
\hline & & Elasmidae & 2 & 2 & Lepidoptera, Hymenoptera \\
\hline & & Encyrtidae & 4 & 11 & Hemiptera (Suborder Sternorrhyncha) \\
\hline & & Eulophidae & 8 & 16 & $\begin{array}{l}\text { Larva Lepidoptera dan Coleoptera, telur } \\
\text { berbagai famili serangga, Arachnida }\end{array}$ \\
\hline & & Eupelmidae & 1 & 1 & Telur berbagai famili serangga \\
\hline & & Eurytomidae & 2 & 2 & Orthoptera, telur Hemiptera \\
\hline 5 & Diaprioidea & Diapriidae & 1 & 2 & Diptera \\
\hline 6 & Evanioidea & Evaniidae & 1 & 2 & Dictyoptera \\
\hline \multirow{2}{*}{7} & \multirow{2}{*}{ Platygastroidea } & Platygastridae & 1 & 1 & Diptera, Coleoptera, Hemiptera \\
\hline & & Scelionidae & 7 & 17 & Terbagai jenis serangga dan Araneae \\
\hline 8 & Ichneumonoidea & Braconidae & 10 & 34 & Diptera, Lepidoptera \\
\hline \multirow{3}{*}{9} & \multirow{3}{*}{ Vespoidea } & Tiphiidae & 1 & 7 & Larva Lepidoptera dan Coleoptera \\
\hline & & Vespidae & 1 & 2 & Lepidoptera, Hymenoptera \\
\hline & & Total & 46 & 137 & \\
\hline
\end{tabular}

Beberapa famili parasitoid seperti Chalcididae, Braconidae, Eulophidae, dan Scelionidae ditemukan hampir di seluruh titik pengambilan sampel (Tabel 3) meskipun memiliki karakteristik yang berbeda. Famili Braconidae tergolong ke dalam jenis parasitoid yang spesifik inang atau spesialis (Wharton, 1997) sehingga keberadaannya pada suatu ekosistem berkaitan erat dengan serangga inang yang tersedia di sana. Parasitoid spesialis umumnya bergantung pada ketersediaan serangga tertentu yang menjadi inangnya (Shaw, 2006). Chalcididae, Eulophidae dan Scelionidae tergolong parasitoid generalis. Chalcididae memarasit pupa Lepidoptera, larva Diptera, serta
Hymenoptera dan Coleoptera. Eulophidae memarasit berbagai telur dan larva serangga lain (Triplehorn \& Johnson, 2005) dan Scelionidae memarasit berbagai telur serangga dan laba-laba sehingga mempunyai potensial inang yang luas (Noyes, 1989; Masner, 1993). Beberapa famili parasitoid ada yang hanya ditemukan pada satu lokasi pengambilan sampel seperti Ceraphronidae (Sains Park), Drynidae (Sains Park), Eucoilidae (Eco Edu Park), Eupelmidae (Taman Buah), Platygastridae (Taman Rektorat) (Tabel 3). Famili Ceraphronidae umumnya memang jarang terkoleksi karena ukuran individu yang sangat kecil (Triplehorn \& Johnson, 2005). 
Pada titik pengambilan sampel Sains Park hampir ditemukan seluruh famili parasitoid. Kondisi ini diduga berkaitan dengan heterogenitas habitat yang meningkatkan interaksi tanamaninang-parasitoid. Sains Park Kampus UNRI merupakan ruang terbuka hijau yang berisi pepohonan, rerumputan, dan danau buatan di dalamnya yang diduga memiliki peranan untuk membentuk mikroklimat yang mendukung kelimpahan dan keanekaragaman parasitoid. Keberadaan taman ini memiliki beberapa tujuan seperti menjadi sarana pendidikan dan penelitian di lokasi alam langsung (eco-campus) sekaligus bertujuan untuk mempertahankan dan mengembangkan plasma nutfah, tanaman, dan keanekaragaman hayati.

Tabel 3. Sebaran famili di tiap lokasi pengambilan sampel

\begin{tabular}{|c|c|c|c|c|c|c|c|c|c|}
\hline \multirow{2}{*}{ No. } & \multirow{2}{*}{ Famili } & \multicolumn{8}{|c|}{ Lokasi Kawasan Hijau } \\
\hline & & LK & LT & EE & TR & $\mathbf{L T}$ & OS & SP & TB \\
\hline 1 & Braconidae & $\sqrt{ }$ & $\sqrt{ }$ & $\sqrt{ }$ & & $\sqrt{ }$ & $\sqrt{ }$ & $\sqrt{ }$ & $\sqrt{ }$ \\
\hline 2 & Ceraphronidae & & & & & & & $\sqrt{ }$ & \\
\hline 3 & Chalcididae & $\sqrt{ }$ & $\sqrt{ }$ & $\sqrt{ }$ & $\sqrt{1}$ & $\sqrt{ }$ & $\sqrt{ }$ & $\sqrt{ }$ & $\sqrt{ }$ \\
\hline 4 & Diapriidae & $\sqrt{ }$ & $\sqrt{ }$ & & & & & & \\
\hline 5 & Drynidae & & & & & & & $\sqrt{ }$ & \\
\hline 6 & Elasmidae & $\sqrt{ }$ & & & & & & & $\sqrt{ }$ \\
\hline 7 & Encyrtidae & $\sqrt{ }$ & & & & & & $\sqrt{ }$ & \\
\hline 8 & Eucoilidae & & & $\sqrt{ }$ & & & & & \\
\hline 9 & Eulophidae & $\sqrt{ }$ & $\sqrt{ }$ & $\sqrt{ }$ & $\sqrt{ }$ & & & $\sqrt{ }$ & $\sqrt{ }$ \\
\hline 10 & Eupelmidae & & & & & & & & $\sqrt{ }$ \\
\hline 11 & Eurytomidae & $\sqrt{ }$ & & & & & & $\sqrt{ }$ & \\
\hline 12 & Evaniidae & & & & $\sqrt{ }$ & $\sqrt{ }$ & & & \\
\hline 13 & Platygastridae & & & & $\sqrt{ }$ & & & & \\
\hline 14 & Scelionidae & $\sqrt{ }$ & $\sqrt{ }$ & $\sqrt{ }$ & & & $\sqrt{ }$ & $\sqrt{ }$ & \\
\hline 15 & Tiphiidae & & & $\sqrt{ }$ & $\sqrt{ }$ & & $\sqrt{ }$ & & \\
\hline 16 & Vespidae & & & $\sqrt{ }$ & & & $\sqrt{ }$ & & \\
\hline
\end{tabular}

\section{Keterangan:}

Tanda $(\sqrt{ })$ menunjukkan famili di temukan.

Lahan Kebun (LK), Lahan Teknik (LT), Eco Edu Park (EE), Taman Rektorat (TR), Lapangan Teknik (LT), Open Space 1 (OS), Sains Park (SP), Taman Buah (TB).

\section{KESIMPULAN}

Famili dengan individu paling melimpah adalah Diptera dan Hymenoptera dengan famili yang paling melimpah adalah Chalcididae (26\%), Braconidae (25\%), diikuti dengan Eulophidae dan Scelionidae masing-masing sebesar $12 \%$. Kelimpahan individu parasitoid ada yang berkaitan dengan kelimpahan inang dan juga diduga berkaitan dengan heterogenitas habitat yang meningkatkan interaksi tanaman-inang-parasitoid. Perlu dilakukan penelitian lanjutan mengenai seberapa besar pengaruh habitat terhadap famili serangga yang berada di kawasan hijau Kampus UNRI.

\section{DAFTAR PUSTAKA}

Asfiya, W., Lach, L., Majer, J. D., Heterick, B., \& Didham, R. K. (2015). Intensive agroforestry practices negatively affect ant (Hymenoptera: Formicidae) diversity and composition in southeast Sulawesi, Indonesia. Asian Myrmecology, 7(1), 87-104.

Firbank, L. G., Petit, S., Smart, S., Blain, A., \& Fuller, R. J. (2008). Assessing the impacts of agricultural intensification on biodiversity: A British perspective. Philosophical Transactions of the Royal Society B: Biological Sciences, 363(1492), 777-787. https://doi.org/10.1098/rstb.2007.2183.

Goulet, H. \& Huber, J.T. (1993). Hymenoptera of the world: and identification guide to families 
(No. 595.79 G8).

Grimaldi, D., \& Engel, M. S. (2005). Evolution of the Insects. Cambridge University Press: New York.

Grissell, E. E., \& Schauff, M. E. (1990). A Handbook of the Families of Nearctic Chalcidoidea (Hymenoptera). The Entomological Society of Washington: Washington.

Hagen, K. S., Mills, N. J., Gordh, G., \& McMurtry, J. A. (1999). Terrestrial Arthropod Predators of Insect and Mite Pests. Handbook of Biological Control, 1985, 383-503. https://doi.org/10.1016/b978-0122573057/50063-1.

Marchiori, C. H. (2019). Parasitoids of Diptera collected in the urban area of Goiânia, Goiás, Brazil. Qeios, 1-5. https://doi.org/10.32388/846248.

Masner L. (1993). Superfamily Platygastroidea. In: Goulet, H., \& Huber, J. T (Eds.). Hymenoptera of the World: An Identification Guide to Families. pp. 558-565. Canada Communications Group: Ottawa.

McAlpine, J. F. (1981). Key to families-adults. In Manual of Nearctic Diptera. Vol. 1. Coordinated by McAlpine, J. F., Peterson, B. V., Shewell, G. E., Teskey, H. J., Vockeroth, J. R., \& Wood, D. M. Agriculture Canada Monograph No. 27. pp. 89-124.

Merritt, R. W., Courtney, G. W., \& Keiper, J. B. (2009). Diptera: (Flies, Mosquitoes, Midges, Gnats). Encyclopedia of Insects, 1, 284-297. https://doi.org/10.1016/B978-0-12-3741448.00085-0.

Noyes, J. S. (1989). A study of five methods of sampling Hymenoptera (Insecta) in tropical rainforest, with special reference to the parasitica. J. Nat. Hist, 23, 285-298.

Nurdin. (2007). Analisa Pemanfaatan Lahan Kampus Binawidya Universitas Riau
Menggunakan Citra Quickbird. Skripsi. Universitas Riau.

Quicke, D. L. J. (1997). Parasitic Wasps. Chapman \& Hall: London.

Rader, R., Bartomeus, I., Tylianakis, J. M., \& Laliberté, E. (2014). The winners and losers of land use intensification: pollinator community disassembly is non-random and alters functional diversity. Diversity and Distributions, 20(8), 908-917. https://doi.org/10.1111/ddi.12221.

Sharkey, M. J. (2007). Phylogeny and classification of hymenoptera. Zootaxa, 548(1668), 521-548. https://doi.org/10.11646/zootaxa.1668.1.25.

Shaw, M. R. (2006). Habitat considerations for parasitic wasps (Hymenoptera). J. Insect. Conserv, 10(2), 17-127.

Triplehorn, C. A., Johnson, N. F., \& Borror, D. J. (2005). Borror and DeLong's Introduction to the Study of Insects. Brooks/Cole Publishing Company: Belmont.

Vitousek, P. M., Mooney, H. A., Lubchenco, J., \& Melillo, J. M. (1997). General - The Rocky Mountain Law Journal. Science, 277(July), 494-499.

Wharton, R. A. (1997). Manual of the new world genera of the family Braconidae (Hymenoptera): introduction. In: Wharton, R. A., Marsh, P. M., \& Sharkey, M. J (Eds.). Manual of the New World Genera of the Family Braconidae (Hymenoptera). pp: 1-12. The International Society of Hymenopterist: Washington.

Wheeler, A. G. (2008). College campuses: patches of insect diversity, opportunities for entomological discovery, and means for enhancing ecological literacy. American Entomologist, 54(1), 18-35. https://doi.org/10.1093/ae/54.1.18.

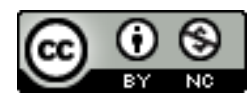

This work is licensed under a Creative Commons Attribution-NonCommercial 4.0 International License 